\title{
Many doctors won't provide assisted dying
}

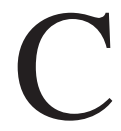

anadian doctors remain deeply divided over whether and how to provide medical aid in dying, and what is required of those who refuse to assist in ending a patient's life.

Earlier this year, the Supreme Court of Canada unanimously ruled that patients who face intolerable suffering from a "grievous and irremediable medical condition" have a constitutional right to doctor-assisted suicide. The decision overturned a previous ban; now federal legislators must regulate the practice by Feb. 6, 2016.

Exactly how physicians should respond to this new legal reality dominated discussion at the Canadian Medical Association (CMA) General Council in Halifax on Aug. 25.

"The debate of whether it's good or not is over," said Jean-Pierre Ménard, a speaker at the meeting and chair of the expert legal panel that recommended in 2013 that Quebec allow medical aid in dying. "Now we have to see how this new right for citizens will be managed and addressed."

According to results of a CMA member survey presented at the meeting, many doctors remain opposed to assisting in a patient's suicide. Only $29 \%$ of those surveyed said they would consider providing medical aid in dying if requested by a patient, $63 \%$ would refuse outright and $8 \%$ were undecided. Of those who would consider providing assistance, fewer would do so in cases of nonterminal illness (43\%) or psychological suffering (19\%).

The online survey, which received 1407 responses, also revealed a diversity of opinion about what physicians should be required to do if they reject a patient's request for medical aid in dying. More than one in four members (29\%) said they shouldn't have to do anything; others supported referring patients to a colleague (19\%), an independent third party $(17 \%)$ or a medical administrator (8\%).

Debate at CMA's General Council

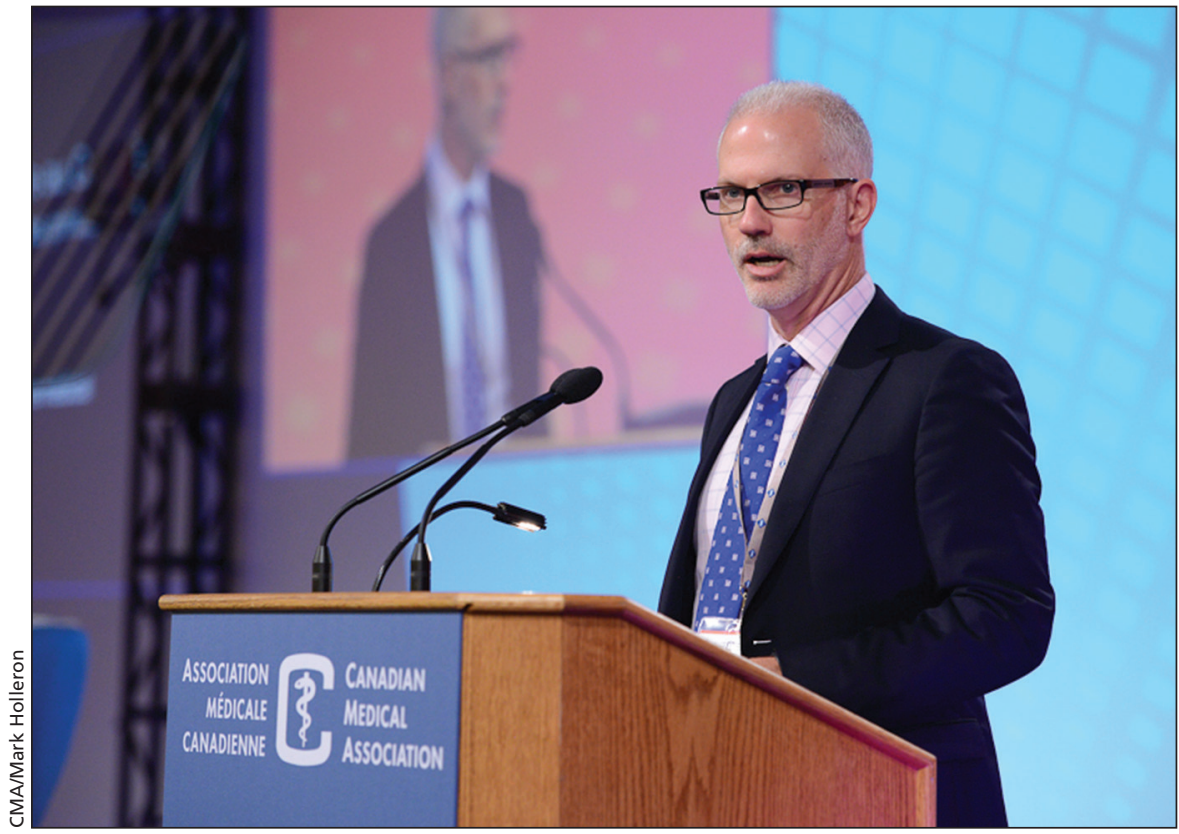

Dr. Jeff Blackmer presented results of a survey that found that $63 \%$ of members would not consider providing assisted suicide to patients.

broke down along similar lines, with some delegates and observers arguing for their right to refuse even indirect assistance to patients seeking to end their lives. For example, this might include refusing to share a patient's chart with a physician providing medical aid in dying.

"No physician should be forced to participate against their conscience," said Dr. Jeff Blackmer, vice president of medical professionalism at CMA. "But there's disagreement about what this means."

Some delegates said CMA should advocate for a separate central information service that patients could access without a referral. This would balance physician autonomy with patients' right to access, they said.

Others argued that conscientious objectors should put their patients' rights first. "A physician who refuses to provide service is serving his own needs, not his patients'," said Dr. Bill Cavers, a British Columbia physician. To not inform is "abandoning the patient, pure and simple," he said.
CMA will consider these comments as it develops guidelines on assisted dying based on ten principles: respect for autonomy, equity, respect for physician values, consent and capacity, clarity, dignity of life, protection of patients, accountability, solidarity and mutual respect.

The guidelines will include recommendations on who should qualify for medical aid in dying, a map for decision-making, the role and responsibilities of physicians, and a framework for moral objection.

Tomorrow, members will vote on a number of motions that will frame the guidelines. Among them, Dr. Ken Burns of BC and Dr. Shawn Whatley of Ontario have moved that CMA policy not include an obligation to refer for medical aid in dying. Whatley also moved that the CMA support a "patient or proxy selfreferral method" for physician-assisted dying. During floor debate Aug. 25, he expressed fears that governments will end up offering assisted suicide as an alternative to better coverage and access to medically necessary care. 
"I have a cousin with a rare kidney disease and right now he has a federal grant to cover [medication] but his financial burden of care could be considered to be so massive that maybe it would be better to choose assisted suicide," he explained.
The importance of quality palliative care will also figure prominently. A motion from Dr. Susan MacDonald, president of the Canadian Society of Palliative Care Physicians, and Dr. Chris Simpson, outgoing president of CMA, will ask the CMA to advocate for access to high-quality palliative care for all Canadians, including those with life-limiting illnesses who are considering assisted death. - Lauren Vogel, CMAJ

CMAJ 2015. DOI:10.1503/cmaj.109-5136 